\title{
Complexation of lithium and sodium cations with $\beta$-phosphorylate ethers, modelling terminal groups of organophosphorus podands. An experimental and theoretical study
}

\author{
A.A. Varnek ${ }^{a}$, J.E. Ten Elshof ${ }^{b}$, A.S. Glebov ${ }^{a}$, V.P. Solov'ev ${ }^{c}$, \\ V.E. Baulin ${ }^{\mathrm{c}}$ and E.N. Tsvetkov ${ }^{\mathrm{c}}$ \\ ${ }^{a}$ Mendeleev Institute of Chemical Technology, Miusskaya Sq. 9, Moscow 125190 (Russian \\ Federation) \\ ${ }^{\mathrm{b}}$ Twente University of Technology, P.O. Box 217, 7500 AE Enschede (The Netherlands) \\ 'Institute of Physiologically Active Substances, Chernogolovka, Moscow 142432 (Russian \\ Federation)
}

(Received 19 March 1992)

\begin{abstract}
The organophosphorus compounds o- $\mathrm{Ph}_{2} \mathrm{P}(\mathrm{O}) \mathrm{C}_{6} \mathrm{H}_{4} \mathrm{OCH}_{3}$ and $\mathrm{Ph}_{2} \mathrm{P}(\mathrm{O}) \mathrm{C}_{2} \mathrm{H}_{4} \mathrm{OCH}_{3}$, which are analogs of podands' terminal groups, have been synthesized. The thermodynamic characteristics of their complexation with LiNCS and NaNCS in acetonitrile were obtained by calorimetry. Molecular mechanics calculations on $\mathbf{M}^{+} \mathrm{L}$ complexes with different stoichiometries $\mathrm{M}^{+}: \mathrm{L}=1: 1,1: 2$ and $1: 4\left(\mathrm{M}^{+}=\mathrm{Li}^{+}, \mathrm{Na}^{+}\right)$were performed, as well as on their solvates with a limited number of $\mathrm{MeCN}$ molecules. It has been shown that the experimental data could be explained by taking into account both the specific features of the complex structure and the solvent effects. The possibility of the application of additive schemes in the investigation of the complexation of polydentate molecules is discussed.
\end{abstract}

\section{INTRODUCTION}

Studies of monopodands which contain phosphoryl terminal groups have shown that these compounds are effective complexation agents with respect to alkali cations [1-6]. According to the data obtained, the stability of podates is defined by both the polyether chain length and the nature of the terminal groups. The latter seems to be especially important, because modification of the phosphorus substituent $R$ (when the polyether chain

Correspondence to: Professor A.A. Varnek, (c/o Professor G. Wipff), Institut Le Bel, 4 rue Blaise Pascal, 67070 Strasbourg, France. 
length is fixed) changes the complexation selectivity of podands considerably.

It is important to study the complexation of $\mathrm{M}^{+}$with fragments of podands, as it will give a potential opportunity to predict the complexation properties of new ligands. Although the thermodynamic characteristics of the complexation of polyethers (glymes) and the structure of their metal complexes have been studied in detail [7-8], there is no corresponding information about the properties of molecules which are analogs of terminal groups of organophosphorus podands.

The aim of the present paper is the synthesis of the compounds $o$ - $\mathrm{Ph}_{2} \mathrm{P}(\mathrm{O}) \mathrm{C}_{6} \mathrm{H}_{4} \mathrm{OCH}_{3}$ (I) and $\mathrm{Ph}_{2} \mathrm{P}(\mathrm{O}) \mathrm{C}_{2} \mathrm{H}_{4} \mathrm{OCH}_{3}$ (II), and an experimental and theoretical study of the features of their complexation with lithium and sodium cations. These compounds were chosen because of the good complexation ability of monopodands which contain corresponding terminal groups with respect to lithium and sodium. Having practically the same hydrocarbon bridge length between phosphorus and the methoxy group oxygen $\left(\mathrm{O}_{\mathrm{m}}\right)$, I and II are essentially different by their conformational properties. Therefore, one can predict that the present study will shed light on the difference between the complexation properties of podands with conformationally rigid and flexible terminal groups $[4,5,7]$.

EXPERIMENTAL AND THEORETICAL METHODS

\section{Synthesis}

\section{2-(Methoxy)phenyl-diphenyl-phosphine oxide (I)}

Product I was prepared by the reaction of $o$-methoxyphenylmagnesium bromide with diphenylphosphinic chloride (for details see ref. 9).

\section{$\beta$-Methoxyethyl-diphenyl-phosphine oxide (II)}

To a stirred solution of $\mathrm{KOH}(0.1 \mathrm{~g}, 1.7 \mathrm{mmoles})$ in methanol $(30 \mathrm{ml})$, diphenylvinylphosphine oxide [10] was added. The mixture was heated at reflux for $3 \mathrm{~h}$. The solvent was evaporated and the residue recrystallized from benzene/hexane to give II, as a white solid; yield $2.7 \mathrm{~g}(62 \%)$; m.p. $82-84^{\circ} \mathrm{C}$.

(Found: C, 69.1; H, 6.6; P, 11.9. $\mathrm{C}_{15} \mathrm{H}_{17} \mathrm{O}_{2} \mathrm{P}$ requires $\mathrm{C}, 69.2 ; \mathrm{H}, 6.6 ; \mathrm{P}$, $11.9 \%) . \quad{ }^{1} \mathrm{HNMR}\left(\mathrm{COCl}_{3} / \mathrm{TMC}\right): \quad \delta \quad 2.64(\mathrm{~m}, 2 \mathrm{H}) ; \quad 3.26(\mathrm{~s}, 3 \mathrm{H}) ; \quad 3.70(\mathrm{~m}, 2 \mathrm{H}) ;$ 7.48(m,6H); 7.76(m,4H).

Measurements of heats of reaction and determination of the thermodynamic characteristics of complexation

The calorimeter LKB-2107 was used for measurements of the heats of 
reaction by means of the calorimetric titration method. Titrations were performed by adding a solution of salt to a solution of the ligand and vice versa. Concentrations of the reagents were $0.0006-0.045 \mathrm{M}$ (LiNCS), $0.0005-$ $0.038 \mathrm{M}$ (NaNCS), $0.015-0.020 \mathrm{M}$ (I) and $0.0010-0.065 \mathrm{M}$ (II). Calculations of the stoichiometry, equilibrium constants and complexation enthalpies were carried out using the CHEM-EQU program package [11]. Details of the dehydration of the salts and the solvent can be found in ref. 5. The errors in the determined thermodynamic parameters are: $\Delta H, \pm 0.5 \mathrm{kcal} \mathrm{mol}^{-1}$; $\Delta S, \pm 2.5 \mathrm{cal} \mathrm{mol}^{-1} \mathrm{~K} ; \lg K, \pm 0.2(1: 1$ complexes $) ; \pm 0.3(1: 2$ and $1: 4$ complexes).

The molecular mechanics force field

The conformational calculations of molecules I and II, their complexes with the cations $\mathrm{Li}^{+}$and $\mathrm{Na}^{+}$and the solvates were performed using the MM2I program package [12-13], which incorporates the Allinger force field [14] for the intramolecular interactions and the modified [12] force field by Claverie and co-workers $[15,16]$ for the ion-molecule or the intermolecular interactions. According to refs. 15 and 16, the intermolecular interaction energy $\left(E_{\mathrm{i}}\right)$ can be written as the sum of electrostatic $\left(E_{\mathrm{es}}\right)$, polarization $\left(E_{\mathrm{pol}}\right)$ and van der Waals $\left(E_{\mathrm{vdW}}\right)$ terms

$E_{\mathrm{i}}=E_{\mathrm{cs}}+E_{\mathrm{pol}}+E_{\mathrm{vdW}}$

The electrostatic term is calculated in the point-charge approximation; the atomic charges $Q_{i}$ are determined in such a way as to reproduce the molecular electrostatic potential (MEP) distribution outside the van de Waals spheres of the atoms (PD charges [17]).

The polarization term is computed [15] using bond polarizability data [18]. The van de Waals interaction energy is calculated by the equation

$E_{\mathrm{vdW}}=\sum_{i} \sum_{j} k_{i j}\left[-\frac{A}{Z_{i j}^{6}}+\left(1-\frac{Q_{i}}{N_{i}}\right)\left(1-\frac{Q_{j}}{N_{j}}\right) B_{0} \exp \left(-\alpha Z_{i j}\right)\right]$

where $Z_{i j}$ is the scaled interatomic distance, $N_{i}$ is the number of valence electrons of atom $i$, and $A, B_{0}$ and $\alpha$ are fixed parameters [15]. The $K_{i j}$ parameters were fitted to reproduce the structural and energy characteristics of model compounds. The total energy of the system under consideration is calculated as the sum of $E_{i}$ and the steric energy $\left(E_{\mathrm{st}}\right)$. The possibility of modelling rather complicated systems including several interacting partners (ligand, cation, anion and some solvent molecules) is the specific feature of this approach, which also takes into account nonadditivity effects. Computations of the geometry and energy characteristics of crown ethers and organophosphorus podands, of their complexes with alkali cations, and of ion pairs [19-20] confirmed the reliability of the employed force field combination. 

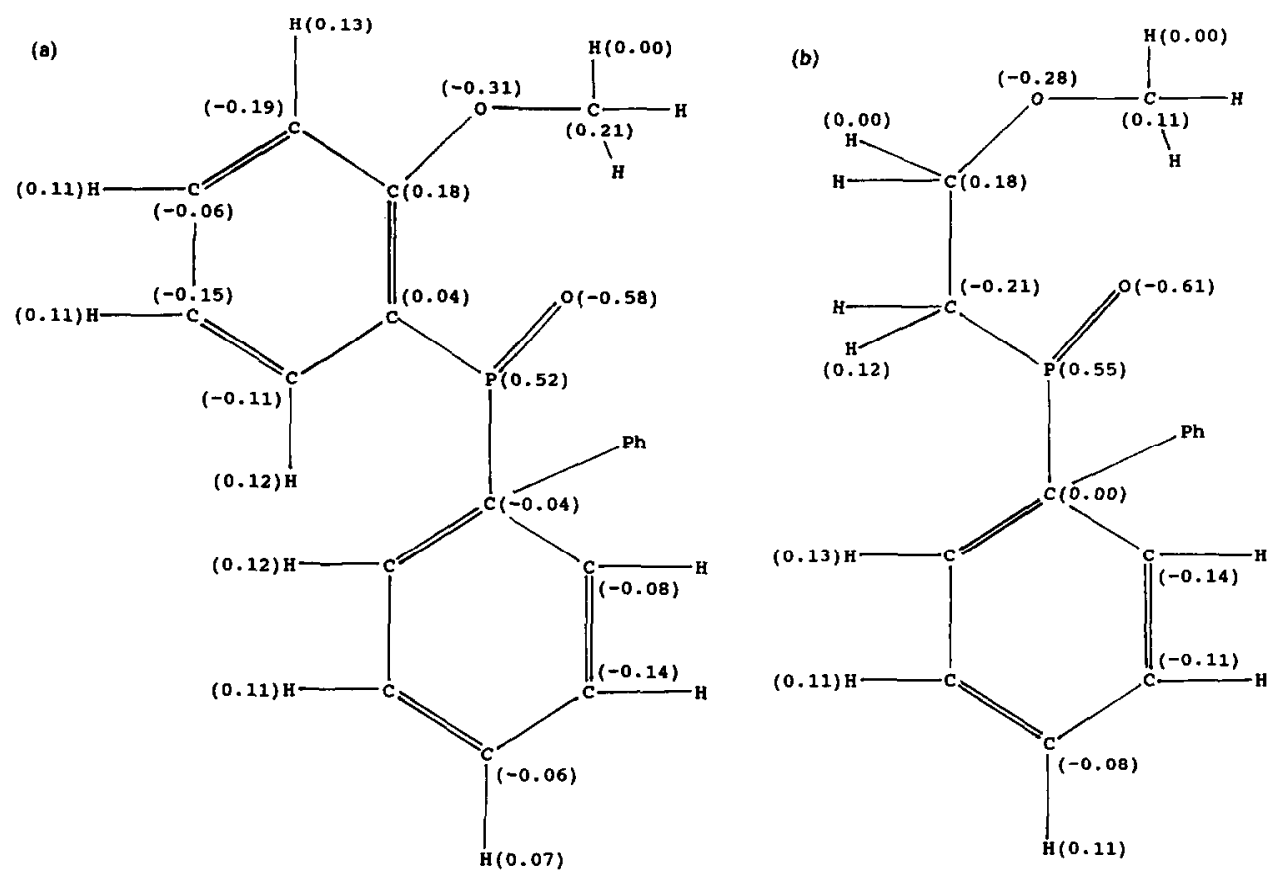

Fig. 1. PD charges of molecule (a) I and (b) II.

The PD charges of I and II, obtained by the least-squares method to reproduce the MEP on Connolly surfaces [21] and computed by the MNDO method using the MOPAC5 package [22] are presented in Fig. 1. The parameters of the applied force field, corresponding to the intramolecular interactions in molecules I and II and their intermolecular interactions with $\mathrm{Li}^{+}$and $\mathrm{Na}^{+}$were taken from ref. 20 .

\section{RESULTS AND DISCUSSION}

\section{Thermodynamics of complexation}

The thermodynamic characteristics of the complexation of I and II with LiNCS and NaNCS in acetonitrile are presented in Table 1. These data show some specific features of the processes under investigation.

(i) For both I and II, complexes with different stoichiometry $\mathrm{M}: \mathrm{L}=1: m$ $(m=1,2,4)$ were found. The complex stability increases with increasing $m$. $\mathrm{Li}^{+}$complexes of I are more stable than the corresponding complexes of II, whereas an opposite tendency is shown for the $\mathrm{Na}^{+}$complexes.

(ii) The complexation enthalpy $(|\Delta H|)$ and $\lg K$ show the same trend only for complexes of II with LiNCS. The $|\Delta H|$ values of LiNCS with I are characterized in almost the same way (taking into account experimental 
TABLE 1

Logarithm of the stability constant $(\lg K)$, enthalpy $\left(\Delta H, \mathrm{kcal} \mathrm{mol}^{-1}\right)$ and entropy $(\Delta S$, cal mol ${ }^{-1} \mathrm{~K}^{-1}$ ) of the complexation of $I$ and II with LiNCS and NaNCS in acetonitrile at $298.15 \mathrm{~K}$

\begin{tabular}{|c|c|c|c|c|c|c|}
\hline \multirow{2}{*}{$\begin{array}{l}\text { Stoichiometry } \\
\text { of complex }\end{array}$} & \multicolumn{3}{|l|}{$\mathbf{I}$} & \multicolumn{3}{|l|}{ II } \\
\hline & $\lg K$ & $\Delta H$ & $\Delta S$ & $\lg K$ & $\Delta H$ & $\Delta S$ \\
\hline \multicolumn{7}{|l|}{ LiNCS } \\
\hline $1: 1$ & 2.03 & -3.0 & -0.9 & 1.92 & -2.0 & 2.1 \\
\hline $1: 2$ & 4.73 & -3.3 & 10.5 & 3.51 & -3.9 & 3.0 \\
\hline $1: 4$ & 8.99 & -3.0 & 31.1 & 6.47 & -4.8 & 13.4 \\
\hline \multicolumn{7}{|l|}{ NaNCS } \\
\hline $1: 1$ & 1.09 & -1.9 & -1.4 & 1.21 & -2.6 & -3.2 \\
\hline $1: 2$ & 1.45 & -1.0 & 3.4 & 1.81 & -1.7 & 2.7 \\
\hline $1: 4$ & 6.34 & -1.7 & 23.5 & 7.25 & -2.2 & 26.0 \\
\hline
\end{tabular}

errors). In general, $|\Delta H|$ of the $\mathrm{Na}^{+}$complexes is lower than the $|\Delta H|$ values of the corresponding $\mathrm{Li}^{+}$complexes.

(iii) The complexation entropy $\Delta S$ increases upon increasing $m$. The complexation entropy values of the $\mathrm{Na}^{+}$complexes with I and II are practically the same. $\Delta S$ values of complexes of LiNCS with I are larger than for complexes of II and they increase with $m$.

\section{STRUCTURE AND ENERGETICS OF THE COMPLEXES ACCORDING TO} MOLECULAR MECHANICS CALCULATIONS

Molecular mechanics was used to calculate the structure and energetics of the free molecules $\mathrm{I}$ and $\mathrm{II}$, their complexes with $\mathrm{Li}^{+}, \mathrm{Na}^{+}$and solvents which include $1: 1$ or 1:2 complexes, and some solvate molecules (MeCN) of the first coordination sphere of the cation.

The complexation energies of complexes without any solvent molecules $\left(E_{\mathrm{c}}\right)$ and those including some solvent molecules $\left(E_{\mathrm{s}}\right)$ were calculated as a sum of the interaction energy $\left(E_{i}\right)$ and the extra-steric energy $\left(\Delta E_{\mathrm{st}}\right)$. The latter is defined by the difference between the steric energy of the ligand in a complex and that of the free molecule.

\section{Complexes of molecule I}

The phosphoryl oxygen atom is out of the plane which includes the atoms of the benzene ring, phosphorus, $\mathrm{O}_{\mathrm{m}}$ and the methyl group carbon (the torsional angle $\mathrm{O}_{\mathrm{p}} \mathrm{PC}_{\mathrm{b}} \mathrm{C}_{\mathrm{b}}$ is $46^{\circ}$ ). The interaction with the cation $\mathrm{M}^{+}$leads to an increase in the polarity of the ligand. The cation coordinates both oxygen atoms (Fig. 2). Its interaction with $\mathrm{O}_{\mathrm{p}}$ is more effective than that with $\mathrm{O}_{\mathrm{m}}$ (Table 2). 


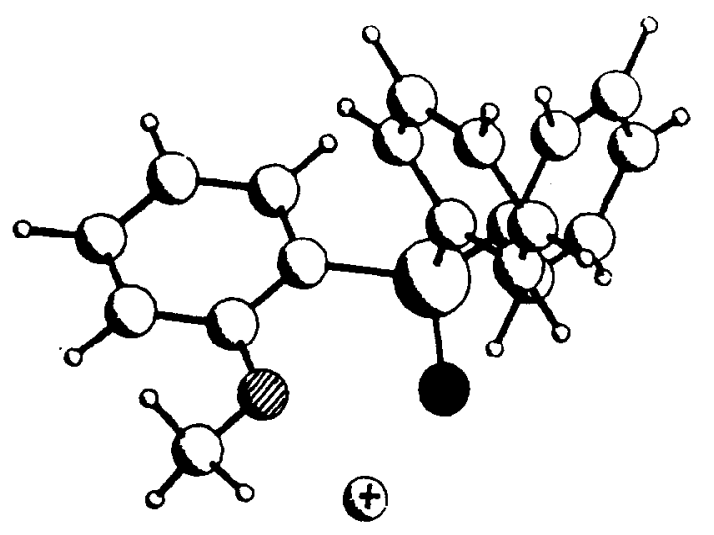

${ }_{\mathrm{p}}^{\mathrm{p}} \mathrm{o}_{\mathrm{m}} \triangleq \mathrm{w}^{+}$

Fig. 2. 1:1 complex of $\mathrm{Li}^{+}$with molecule $\mathbf{I}$.

For the $1: 2$ complexes, two stable conformers with planar (s) and tetrahedral $(t)$ coordination of the cation were found (Fig. 3). In the s-complexcs, the cation is situated in the centre of the parallelogram of the ligand oxygen atoms. The lengths of the sides of the parallelogram are 2.57 and $3.42 \AA$ in $\mathrm{Li}^{+}$complexes, and 2.70 and $3.87 \AA$ in $\mathrm{Na}^{+}$complexes. The torsional angles $\mathrm{O}_{\mathrm{p}}(1) \mathrm{O}_{\mathrm{m}}(1) \mathrm{O}_{\mathrm{p}}(2) \mathrm{O}_{\mathrm{m}}(2)$ in the $t$-complexes of $\mathrm{Li}^{+}\left(\mathrm{Na}^{+}\right)$were found to be $70^{\circ}\left(83^{\circ}\right)$, whereas in an ideal tetrahedron this angle is $71^{\circ}$. Interactions between ligands lead to some changes in the coordination bond lengths in comparison with $1: 1$ complexes. The distance $\mathrm{M}^{+} \cdots \mathrm{O}_{\mathrm{m}}$ is almost the same in the $t$-complexes, whereas it increased by $0.1 \AA$ in the $s$-complex of $\mathrm{Li}^{+}$, and

\section{TABLE 2}

Cation-oxygen distances $(\AA)$ in complexes of $\mathrm{I}$ and $\mathrm{II}$ with $\mathrm{Li}^{+}$and $\mathrm{Na}^{+}$

\begin{tabular}{|c|c|c|c|c|c|}
\hline \multirow[t]{2}{*}{ Molecule } & \multirow{2}{*}{$\begin{array}{l}\text { Stoichiometry } \\
\text { of complex }\end{array}$} & \multicolumn{2}{|l|}{$\mathrm{Li}^{+}$} & \multicolumn{2}{|l|}{$\mathrm{Na}^{+}$} \\
\hline & & $\mathbf{M}^{+} \cdots \mathrm{O}_{\mathrm{p}}$ & $\mathbf{M}^{+} \cdots \mathrm{O}_{\mathrm{m}}$ & $\mathbf{M}^{+} \cdots \mathrm{O}_{\mathrm{p}}$ & $\mathrm{M}^{+} \cdots \mathrm{O}_{\mathrm{m}}$ \\
\hline \multirow[t]{4}{*}{ I } & $1: 1$ & 1.85 & 2.14 & 2.16 & 2.55 \\
\hline & $1: 2(s)$ & 1.93 & 2.24 & 2.19 & 2.51 \\
\hline & $1: 2(t)$ & 1.87 & 2.15 & 2.19 & 2.57 \\
\hline & $1: 4$ & 2.17 & 3.74 & 2.39 & 3.80 \\
\hline \multirow[t]{4}{*}{ II } & $1: 1$ & 1.90 & 2.11 & 2.16 & 2.47 \\
\hline & $1: 2(s)$ & 1.92 & 2.34 & 2.19 & 2.51 \\
\hline & $1: 2(t)$ & 1.90 & 2.22 & 2.18 & 2.50 \\
\hline & $1: 4$ & 2.06 & 5.00 & 2.41 & 4.89 \\
\hline
\end{tabular}


(a)

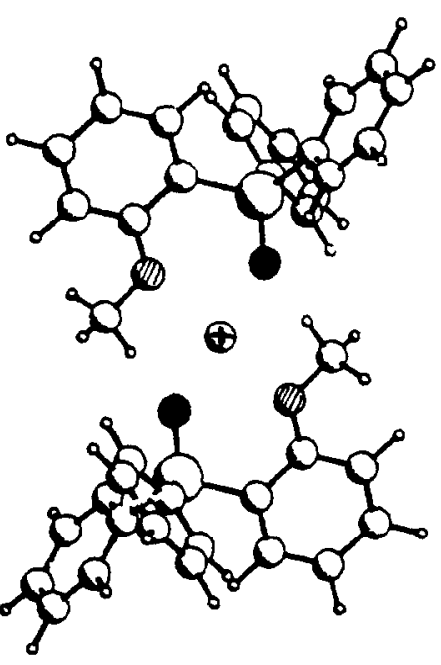

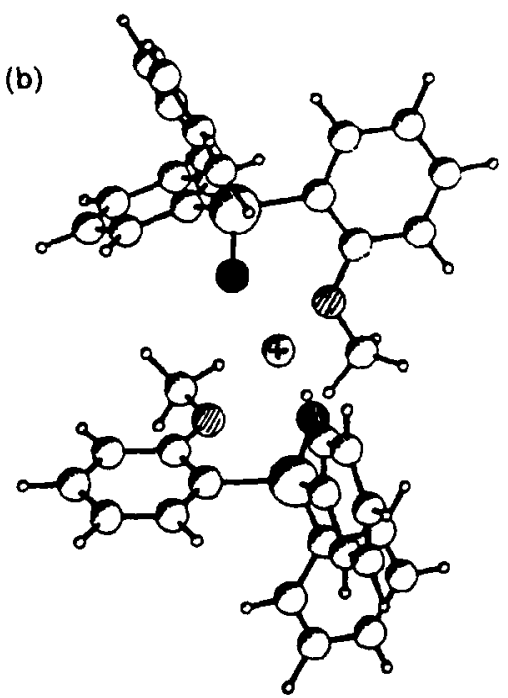

Fig. 3. $1: 2$ complexes of molecule I with $\mathrm{Li}^{+}$(a) $s$-type (b) $t$-type.

decreased by $0.04 \AA$ in the corresponding $\mathrm{Na}^{+}$complex. As the distance $\mathrm{M}^{+} \cdots \mathrm{O}_{\mathrm{p}}$ in the complexes of both types were found to be practically the same, the differences in the $\mathrm{M}^{+} \cdots \mathrm{O}_{\mathrm{m}}$ distances must specify the difference in the $s / t$-complex stability in vacuum (see Table 2).

The $t$-coordination of $\mathrm{Li}^{+}$is $2 \mathrm{kcalmol}^{-1}$ more favorable than the $s$-coordination, whereas the $s$-complex of $\mathrm{Na}^{+}$was found to be $1.6 \mathrm{kcal} \mathrm{mol}^{-1}$ more stable than the corresponding $t$-complex (Table 3 ). Increasing the number of ligands in the complexes from two to four leads to the removal of the $\mathrm{O}_{\mathrm{m}}$ atoms from the coordination sphere of the cation, the latter being

\section{TABLE 3}

$\Delta E_{\mathrm{st}}$ and $\Delta E_{\mathrm{c}}\left(\mathrm{kcal} \mathrm{mol}^{-1}\right)$ in the complexes of I and II with $\mathrm{Li}^{+}$and $\mathrm{Na}^{+}$

\begin{tabular}{|c|c|c|c|c|c|c|c|}
\hline \multirow[t]{2}{*}{ Molecule } & \multirow{2}{*}{$\begin{array}{l}\text { Stoichiometry } \\
\text { of complex }\end{array}$} & \multicolumn{3}{|l|}{$\mathrm{Li}^{+}$} & \multicolumn{3}{|l|}{$\mathrm{Na}^{+}$} \\
\hline & & $-\Delta E_{\mathrm{c}}$ & $-\Delta E_{\mathrm{c}} / n$ & $\Delta E_{\mathrm{st}}$ & $-\Delta E_{\mathrm{c}}$ & $-\Delta E_{\mathrm{c}} / n$ & $\Delta E_{\mathrm{st}}$ \\
\hline \multirow[t]{4}{*}{ I } & $1: 1$ & 61.1 & & 1.6 & 45.3 & & 1.0 \\
\hline & $1: 2(s)$ & 110.5 & 55.3 & 2.3 & 85.1 & 42.6 & 1.2 \\
\hline & $1: 2(t)$ & 112.5 & 56.3 & 1.8 & 83.5 & 41.8 & 2.1 \\
\hline & $1: 4$ & 164.0 & 41.0 & 2.7 & 144.1 & 36.0 & 2.5 \\
\hline \multirow[t]{4}{*}{ II } & $1: 1$ & 64.8 & & 3.7 & 50.8 & & 0.7 \\
\hline & $1: 2(s)$ & 115.7 & 57.8 & 2.8 & 92.0 & 47.0 & 1.1 \\
\hline & $1: 2(t)$ & 111.2 & 55.6 & 7.6 & 90.9 & 45.5 & 1.2 \\
\hline & $1: 4$ & 161.6 & 40.4 & 0.2 & 130.6 & 32.7 & 0.0 \\
\hline
\end{tabular}


(a)
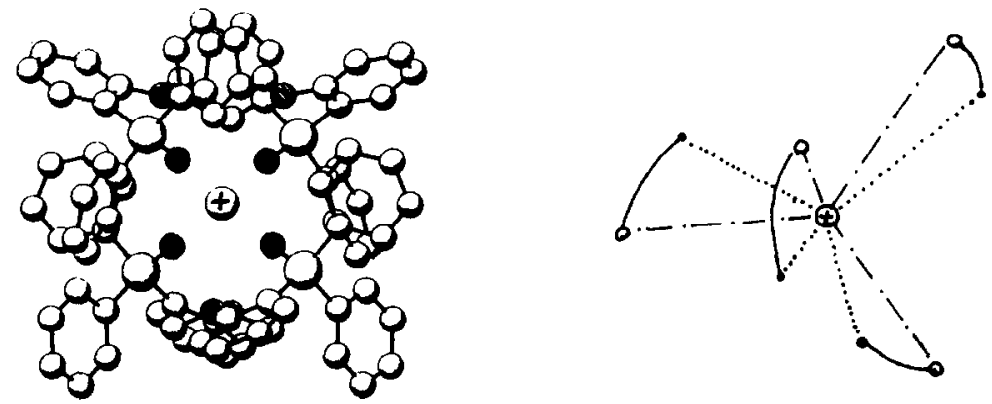

(b)
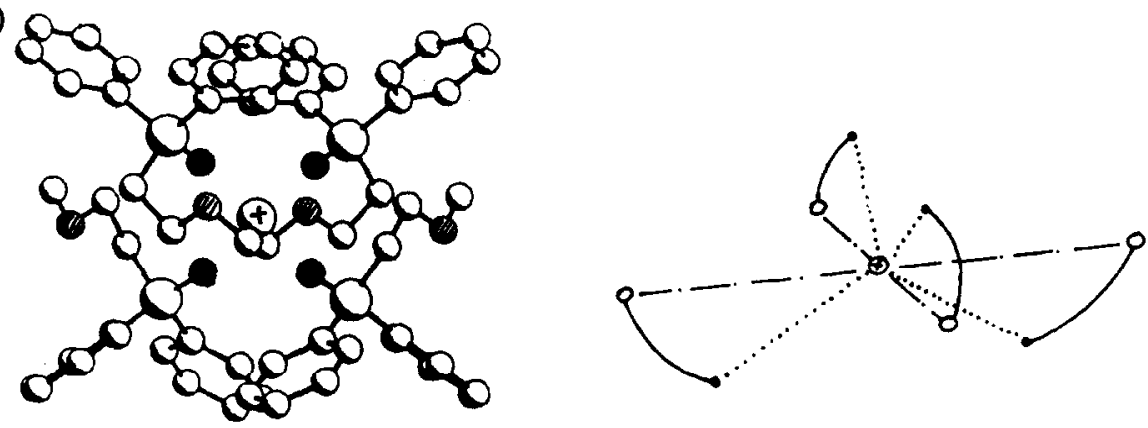

Fig. 4. 1:4 complexes of $\mathrm{Na}^{+}$with (a) molecule I (b) molecule II.

situated in a tetrahedral surrounding of $\mathrm{O}_{\mathrm{p}}$ atoms (Fig. 4(a)). The $\mathrm{O}_{\mathrm{m}}$ atoms are situated relatively far away from the cation; at $3.74 \AA$ for $\mathrm{Li}^{+}$and $3.80 \AA$ for $\mathrm{Na}^{+}$. They form a second tetrahedral coordination sphere. The $\mathrm{M}^{+} \cdots \mathrm{O}_{\mathrm{p}}$ distances increase by $0.16 \AA\left(\mathrm{Li}^{+}\right)$and $0.22 \AA\left(\mathrm{Na}^{+}\right)$in comparison with the $1: 1$ complexes. The difference between the radii of the $\mathrm{Li}^{+}$and the $\mathrm{Na}^{+}$ complexes, which are defined by the distance $\mathrm{M}^{+} \cdots \mathrm{O}_{\mathrm{p}}$, is $0.22 \AA$; this is considerably less than the difference between the ion radii of $\mathrm{Li}^{+}$and $\mathrm{Na}^{+}$ $(0.31 \AA)[23]$. The specific feature of the above complexes is the similarity of the geometry parameters of ligands in the complexes of different stoichiometry and the free molecule $\mathbf{I}$.

\section{Complexes of molecule II}

The essential difference between molecules I and II is the possibility of free rotation around the $\mathrm{C}-\mathrm{C}$ bond in the latter; hence, two conformers with different PCCO torsional angles are possible: (+)gauche (IIa) and (-)gauche (IIb). Conformer IIa is characterized by a relatively large distance between the oxygen atoms $(3.7 \AA)$ and therefore only one of the oxygen atoms can bind to the cation, whereas in IIb both oxygen atoms are able to coordinate with the cation (distance $\mathrm{O}_{\mathrm{p}} \cdots \mathrm{O}_{\mathrm{m}}=2.7 \AA$ ). Therefore, it 
is not surprising that the ligand accepts conformation IIb in $1: 1$ and $1: 2$ $(s, t)$-complexes and IIa in $1: 4$ complexes where the cation only coordinates $\mathrm{O}_{\mathrm{p}}$ atoms.

$1: 2 \mathrm{~s}$-Complexes with planar positions of donor atoms appear to be more stable than $t$-complexes with a tetrahedral coordination of the cation, both for $\mathrm{Li}^{+}$and $\mathrm{Na}^{+}$. It should be noted that the $\mathrm{M}^{+} \cdots \mathrm{O}$ distances were found to be smaller for the $t$-coordination of the cation (Table 2), which corresponds with a stronger interaction between the cation and the ligands. However, in the case of the $t$-complexes, the changes in steric energy of the ligands are considerably larger than for the $s$-complexes (Table 3 ). Thus, the $s$-complexes are more stable than the $t$-complexes.

Analogous to the complexes of $I$, an increase in the number of ligands in the coordination sphere of the cation in II leads to the increase in the $\mathrm{M}^{+} \cdots \mathrm{O}$ distance. Thus, the coordination bond lengths $\mathrm{M}^{+} \cdots \mathrm{O}_{\mathrm{p}}$ increased by $0.02-0.03 \AA\left(\mathrm{Li}^{+}, \mathrm{Na}^{+}\right)$in $1: 2$ complexes, and by $0.16 \AA\left(\mathrm{Li}^{+}\right)$and $0.25 \AA$ $\left(\mathrm{Na}^{+}\right)$in $1: 4$ complexes. The range of $\mathrm{M}^{+} \cdots \mathrm{O}_{\mathrm{m}}$ distances in $1: 2$ complexes is wider: $0.11-0.23 \AA\left(\mathrm{Li}^{+}\right)$and $0.03-0.04 \AA\left(\mathrm{Na}^{+}\right)$. In $1: 4$ complexes the cation is coordinated tetrahedrally by the phosphoryl oxygen atoms, whereas the $\mathrm{O}_{\mathrm{m}}$ atoms lie in one plane with the cation; corresponding $\mathrm{M}^{+} \cdots \mathrm{O}_{\mathrm{m}}$ distances are $5.00 \AA\left(\mathrm{Li}^{+}\right)$and $4.89 \AA\left(\mathrm{Na}^{+}\right)$(Fig. 4(b)). The extent of removal of $\mathrm{O}_{\mathrm{m}}$ atoms from the coordination sphere of the cation is more pronounced for the complexes of II, in comparison with I, due to the flexibility of the former.

The energy characteristics of the complexes are presented in Table 3. From these data it follows that in its $1: 1$ and $1: 2$ complexes, the interaction between $\mathrm{M}^{+}$and $\mathrm{II}$ is stronger than that between $\mathrm{M}^{+}$and $\mathrm{I}$. This might be explained by the conformational flexibility of II, which allows a more effective interaction with the cation in comparison with the rigid molecule I. The effectivity of the cation-ligand interaction, which is defined by $\left|E_{\mathrm{c}} / m\right|$, decreases upon increasing $m$. Changes in the steric energies of the ligand do not make a large contribution to $E_{\mathrm{c}}$. The biggest $\Delta E_{\mathrm{st}}$ value was obtained for the $t$-complex of $\mathrm{Li}^{+}$, where it contributes only $6.8 \%$ to the overall complexation energy.

\section{Solvates of the complexes of molecules I and II}

To simulate the solvation shells of the $1: 1$ and $1: 2$ complexes, we assumed that the coordination sphere of the cation included no more than six donor atoms. Thus, the compositions of the solvate under consideration are $\mathrm{M}^{+} \cdot \mathrm{L} \cdot 4 \mathrm{~S}$ and $\mathrm{M}^{+} \cdot 2 \mathrm{~L} \cdot 2 \mathrm{~S}$, where $\mathrm{S}=\mathrm{MeCN}$.

In solvates $\mathrm{M}^{+} \cdot \mathrm{L} \cdot 4 \mathrm{~S}(\mathrm{~L}=\mathrm{I})$, the coordination polyhedron is an octahedron. Both oxygen atoms and two nitrogen atoms of the solvent lie in one plane with the cation. Two other MeCN molecules coordinate the cation 
from axial positions. The solvates of the $\mathrm{M}^{+} \cdot 2 \mathrm{~L}$ complexes of the $s$-type, where $\mathrm{MeCN}$ molecules are in axial positions, are also octahedral. However, the structure of the coordination spheres of $\mathrm{Li}^{+}$and $\mathrm{Na}^{+}$in the solvates of the $t$-complexes is quite different. The coordination polyhedron of $\mathrm{Li}^{+}$is a trigonal bipyramid. One of its bases includes two nitrogen atoms of the solvent and one $\mathrm{O}_{p}$ atom of the first ligand, and the other base includes two oxygen atoms of the second ligand and the $\mathrm{O}_{\mathrm{m}}$ atom of the first. In the corresponding solvate of the $\mathrm{Na}^{+}$complex, only one solvent molecule coordinates with the cation; the second MeCN molecule is removed from the cation's coordination sphere. The cation's coordination polyhedron is a disturbed tetragonal pyramid, in which the atoms $\mathrm{O}_{\mathrm{m}}(1), \mathrm{N}, \mathrm{O}_{\mathrm{p}}(2)$ and $\mathrm{O}_{\mathrm{m}}(2)$ form the base; $\mathrm{O}_{\mathrm{p}}(1)$ is situated on the top of the pyramid. From Table 4 , it follows that the interaction with solvent molecules leads to consider-

\section{TABLE 4}

Cation-oxygen and cation-nitrogen distances $(\AA)$ in the solvated complexes of I and II with $\mathrm{Li}^{+}$and $\mathrm{Na}^{+}$

\begin{tabular}{|c|c|c|c|c|c|}
\hline \multirow[t]{2}{*}{ Molecule } & \multirow{2}{*}{$\begin{array}{l}\text { Stoichiometry } \\
\text { of complex }\end{array}$} & \multicolumn{2}{|l|}{$\mathrm{Li}^{+}$} & \multicolumn{2}{|l|}{$\mathrm{Na}^{+}$} \\
\hline & & $\mathbf{M}^{+} \cdots \mathrm{O}_{\mathbf{p}}$ & $\mathrm{M}^{+} \cdots \mathrm{O}_{\mathbf{m}}$ & $\mathrm{M}^{+} \cdots \mathrm{O}_{\mathrm{p}}$ & $\mathrm{M}^{+} \cdots \mathrm{O}_{\mathrm{m}}$ \\
\hline \multirow[t]{3}{*}{$\mathbf{I}$} & $1: 1$ & 1.88 & 2.30 & 2.26 & 2.72 \\
\hline & $1: 2(s)$ & 1.94 & $2.31-2.34$ & 2.22 & $2.68-2.74$ \\
\hline & $1: 2(t)$ & $1.89-1.93$ & $2.41-2.43$ & 2.22 & $2.68-2.74$ \\
\hline \multirow[t]{4}{*}{ II } & $1: 1$ & 1.89 & 2.25 & 2.27 & 2.82 \\
\hline & $1: 2(s)$ & 1.94 & $2.34-2.39$ & 2.20 & 2.54 \\
\hline & $1: 2(t)$ & 1.89 & $2.16-2.22$ & 2.21 & $2.55-2.67$ \\
\hline & & \multicolumn{2}{|l|}{$\mathbf{M}^{+} \cdots \mathbf{N}$} & \multicolumn{2}{|l|}{$\mathbf{M}^{+} \cdots \mathbf{N}$} \\
\hline \multirow[t]{3}{*}{$\mathbf{I}$} & $1: 1$ & \multicolumn{2}{|l|}{2.292 .53} & \multicolumn{2}{|l|}{$2.37-2.45$} \\
\hline & $1: 2(s)$ & \multicolumn{2}{|l|}{$2.31-2.33$} & \multicolumn{2}{|l|}{$2.45-2.46$} \\
\hline & $1: 2(t)$ & \multicolumn{2}{|l|}{$2.54-2.65$} & \multicolumn{2}{|l|}{$2.36-3.72$} \\
\hline \multirow[t]{3}{*}{ II } & $1: 1$ & \multicolumn{2}{|l|}{$2.36-2.80$} & \multicolumn{2}{|l|}{$2.43-2.59$} \\
\hline & $1: 2(s)$ & \multicolumn{2}{|l|}{$2.56-2.58$} & \multicolumn{2}{|l|}{$2.75-2.82$} \\
\hline & $1: 2(t)$ & \multicolumn{2}{|l|}{$2.73-3.60$} & \multicolumn{2}{|l|}{$2.39-3.26$} \\
\hline
\end{tabular}

able changes in the $\mathbf{M}^{+} \cdots \mathrm{O}$ distances. This appears in solvates of $1: 1$ complexes, especially where the coordination bond lengths $\mathbf{M}^{+} \cdots \mathrm{O}_{\mathrm{m}}$ increase by $0.16 \AA\left(\mathrm{Li}^{+}\right)$and $0.25 \AA\left(\mathrm{Na}^{+}\right)$. In solvents of $1: 2$ complexes $(t)$ the corresponding changes were $0.25 \AA\left(\mathrm{Li}^{+}\right)$and $0.13 \AA\left(\mathrm{Na}^{+}\right)$. The biggest change in $\mathrm{M}^{+} \cdots \mathrm{O}_{\mathrm{p}}$ distance was found in solvates of the $t$-complex of $\mathrm{Li}^{+}$ $(0.07-0.08 \AA)$. 


\section{TABLE 5}

$\Delta E_{\mathrm{st}}$ and $\Delta E_{\mathrm{s}}\left(\mathrm{kcal} \mathrm{mol}^{-1}\right)$ in the solvated complexes of $\mathrm{I}$ and II with $\mathrm{Li}^{+}$and $\mathrm{Na}^{+}$

\begin{tabular}{|c|c|c|c|c|c|}
\hline \multirow[t]{2}{*}{ Molecule } & \multirow{2}{*}{$\begin{array}{l}\text { Stoichiometry } \\
\text { of complex }\end{array}$} & \multicolumn{2}{|l|}{$\mathrm{Li}^{+}$} & \multicolumn{2}{|l|}{$\mathrm{Na}^{+}$} \\
\hline & & $-\Delta E_{\mathrm{g}}^{\prime}$ & $\Delta E_{\mathrm{st}}$ & $-\Delta E_{\mathrm{s}}$ & $\Delta E_{\mathrm{st}}$ \\
\hline \multirow[t]{3}{*}{ I } & $1: 1$ & 102.6 & 1.2 & 89.6 & 0.7 \\
\hline & $1: 2(s)$ & 127.1 & 1.1 & 103.9 & 1.0 \\
\hline & $1: 2(t)$ & 120.6 & 3.3 & 95.9 & 1.7 \\
\hline \multirow[t]{3}{*}{ II } & $1: 1$ & 102.9 & 3.5 & 89.8 & 0.8 \\
\hline & $1: 2(s)$ & 128.5 & 2.0 & 106.1 & 1.5 \\
\hline & $1: 2(t)$ & 126.9 & 7.5 & 105.3 & 1.8 \\
\hline
\end{tabular}

The structures of the solvates of the $1: 1 \mathrm{Li}^{+}$complex of II, and the $\mathrm{Li}^{+}$ and $\mathrm{Na}^{+} 1: 2$ complexes (s) (Fig. 5) are analogous to those of the corresponding complexes of $I$. The coordination sphere of $\mathrm{Na}^{+}$in the solvate of its $1: 1$ complex includes four nitrogen atoms which lie in a plane and coordinate the cation from one side; the ligand oxygen atoms coordinate $\mathrm{Na}^{+}$from the other side (Fig. 6). The coordination polyhedron of $\mathrm{Li}^{+}$in the solvate of its

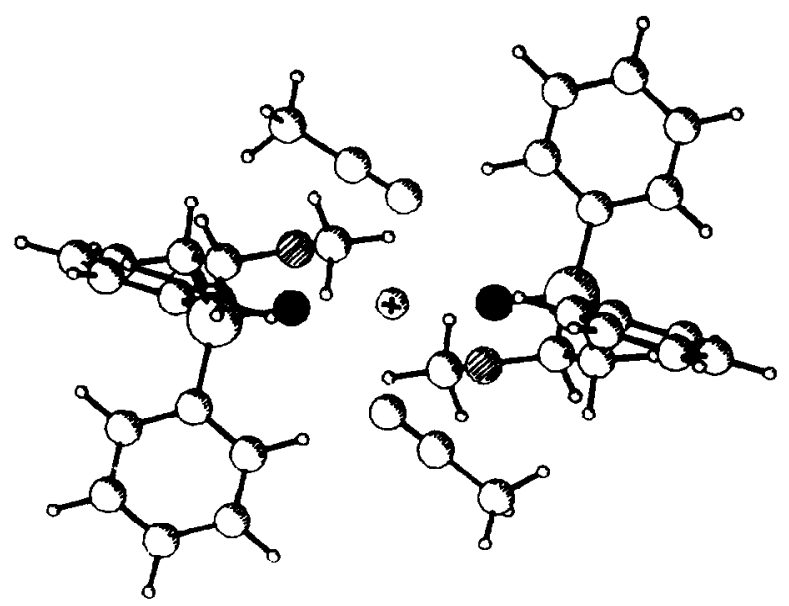

Fig. 5. Solvate of the 1:2 s-type complex of $\mathrm{Li}^{+}$with molecule II. 

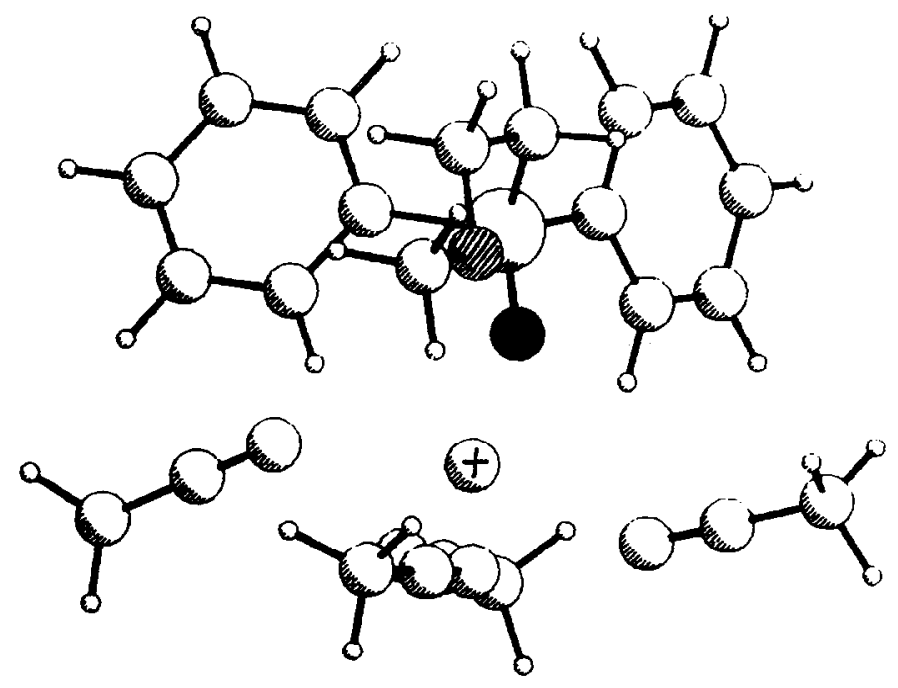

Fig. 6. Solvate of the $1: 1$ complex of $\mathrm{Na}^{+}$with molecule II.

$t$-complex is similar to the coordination polyhedron of $\mathrm{Na}^{+}$in the solvate of its $t$-complex with $\mathbf{I}$. Only one acetonitrile molecule interacts with the cation in the solvate of the $\mathrm{Na}^{+} t$-complex of II. The line $\mathrm{Na}^{+} \cdots \mathrm{N}$ is perpendicular to the base of the tetrahedron, which is formed by the atoms $O_{m}(1), O_{p}(1)$ and $O_{m}(2)$.

As a rule, interaction with the solvent leads to smaller changes in $\mathrm{M}^{+}$... O distances for complexes of II compared with those of $\mathbf{I}$. However, the interaction between complexes of II and MeCN is less effective: the $\mathrm{M}^{+} \cdots \mathrm{N}$ distances are considerably larger than in the corresponding solvates of I (Table 4). An analysis of the solvates' energy characteristics proves the greater stability of $s$-complexes in solution compared with $t$-complexes, due to the better availability of the cation for solvent molecules.

To study the solvation features of the free molecules I and II, we assumed that both of them could interact with two acetonitrile molecules directly. The structures of the solvates of I and IIb are similar (Fig. 7). One MeCN molecule forms an $\mathrm{H}$-bond $\mathrm{O}_{\mathrm{p}} \cdots \mathrm{H}-\mathrm{C}$ with length $2.46 \AA$. The other solvent molecule realizes its bonds both with $\mathrm{O}_{\mathrm{p}}\left(2.76 \AA\right.$ (I) and $2.72 \AA$ (II)) and $\mathrm{O}_{\mathrm{m}}$ $(2.68 \AA$ (I) and $3.08 \AA$ (IIb)). The interaction energies of I and IIb with solvent molecules differ insignificantly, and are equal to $-8.0 \mathrm{kcal} \mathrm{mol}^{-1}$ (IIb) and $-7.6 \mathrm{kcal} \mathrm{mol}^{-1}$ (I). It should be noted that the conformer IIa, with its oxygen atoms pointing in reverse directions, is less solvated than IIb $\left(-4.2 \mathrm{kcal} \mathrm{mol}^{-1}\right)$.

The above results indicate that the cation $\mathrm{M}^{+}$interacts more effectively 


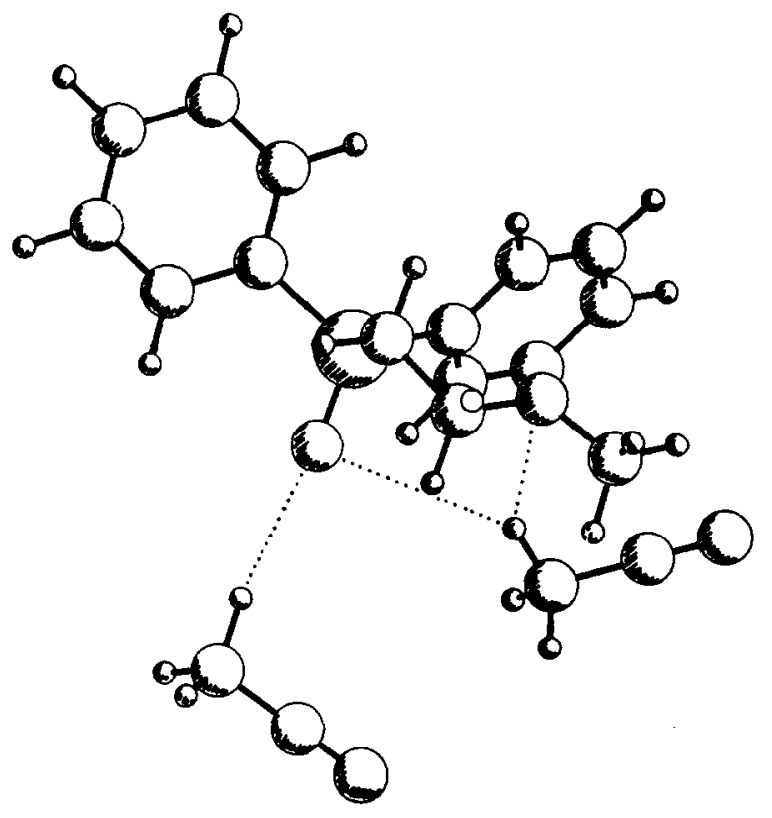

Fig. 7. Solvate of molecule II.

with the phosphoryl oxygen than with the ether (anisole) oxygen. This is manifested in small changes in the $\mathrm{M}^{+} \cdots \mathrm{O}_{\mathrm{p}}$ distances in comparison with the $\mathrm{M}^{+} \ldots \mathrm{O}_{\mathrm{m}}$ ones in several complexes of different types. A similar tendency is found for the complexes of lithium and sodium with organophosphorous podands, where the lengths of the coordination bonds $\mathrm{M}^{+} \cdots \mathrm{O}_{\mathrm{p}}$ are practically independent of the lengths of the polyether chain, whereas the distances between the cation and the anisole oxygen (or terminal ether oxygen) are changed [20]. On the whole, these data correspond with well-known ideas of complexation mechanisms of podands, which contain donor centers in their terminal groups: polyether chain oxygen atoms arrange around the cation which is already strongly bound to the terminal groups' donor atoms [7].

\section{Analysis of complexation thermodynamics}

We now consider the question of whether the calculated data can reproduce the tendency of $\Delta H$ changes for the complexes of I and II with the same stoichiometry. According to the thermodynamic cycle model [19], the difference in complexation energies $\left(\delta E_{i, j}^{\mathrm{M}+}\right)$ of the cation $\mathrm{M}^{+}$with ligands $\mathrm{L}_{\mathrm{i}}$ and $\mathrm{L}_{j}$ is defined by a sum of terms. These are the difference in interaction energies of $L_{i}$ and $L_{j}$ in vacuum, the difference in solvation energies of the complexes $L_{i} M^{+}$and $L_{j} M^{+}$, and the difference in desolvation energies 
$\delta\left(E_{\mathrm{s}}^{0}\right)_{i, j}$ of the free molecules $\mathrm{L}_{i}$ and $\mathrm{L}_{j}$. In our case it is obvious that $\delta\left(E_{\mathrm{s}}^{0}\right)_{i, j}$ should be calculated by taking into account the number of ligands $m$ in the complex:

$\delta\left(E_{\mathrm{s}}^{0}\right)_{i, j}=-\left[\left(E_{\mathrm{s}}^{0}\right)_{\mathbf{I}}-\left(E_{\mathrm{s}}^{0}\right)_{\mathrm{II}}\right] \times m$

The sum of the other components of $\delta E_{i, j}^{\mathrm{M}+}$ is equal to the difference in $E_{\mathrm{s}}$ values, corresponding with the solvates of the I and II complexes with $\mathrm{M}^{+}$ $\left(\left(E_{\mathrm{s}}^{\mathrm{M}+}\right)_{\mathrm{I}}\right.$ and $\left.\left(E_{\mathrm{s}}^{\mathrm{M}+}\right)_{\mathrm{II}}\right)$. Hence

$\delta E_{\mathrm{I}, \mathrm{II}}^{\mathrm{M}+}=\left[\left(E_{\mathrm{s}}^{\mathrm{M}+}\right)_{\mathrm{I}}-\left(E_{\mathrm{s}}^{\mathrm{M}+}\right)_{\mathrm{II}}\right]-\left[\left(E_{\mathrm{s}}^{0}\right)_{\mathrm{I}}-\left(E_{\mathrm{s}}^{0}\right)_{\mathrm{II}}\right] \times m$

The values of $\delta E_{\mathrm{I}, \mathrm{II}}^{\mathrm{M}+}\left(\mathrm{kcal} \mathrm{mol}^{-1}\right)$, which were obtained using data from Tables 3 and 5 and the solvation energies of the free molecules I and II are respectively: $0.7\left(\mathrm{Li}^{+}\right), 0.6\left(\mathrm{Na}^{+}\right)$in $1: 1$ complexes; $2.2\left(\mathrm{Li}^{+}\right), 3.0\left(\mathrm{Na}^{+}\right)$in $1: 2$ complexes; $-0.8\left(\mathrm{Li}^{+}\right),-11.8\left(\mathrm{Na}^{+}\right)$in $1: 4$ complexes $\left(E_{\mathrm{c}}\right.$ values were used herc).

The comparison of these data with Table 1 shows that the calculations qualitatively reproduced the tendency of $\Delta H$ changes for the $1: 2$ complexes (where differences in enthalpy $\left(\Delta(\Delta H)_{\mathrm{I}, \mathrm{II}}\right)$ are $0.6 \mathrm{kcal} \mathrm{mol}^{-1}$ (LiNCS) and $0.7 \mathrm{kcal} \mathrm{mol}^{-1}$ (NaNCS)) as well as for the $\mathrm{Na}^{+} 1: 1$ complex $\left(\Delta(\Delta H)_{\mathrm{I}, \mathrm{II}}=0.7 \mathrm{kcal} \mathrm{mol}^{-1}\right)$. The reason for the discrepancy between the calculated and experimental data is probably related to a correct but insufficient procedure for the estimation of the solvation energies. Only the interaction with the solvent molecules in the closest surroundings was taken into account. However, interactions with solvent molecules that coordinate with neither the cation nor the oxygen atoms of the free molecules could be rather important. This is most obvious in the case of the $1: 4$ complexes. The complex $\mathrm{Li}^{+} \cdot \mathrm{L}_{4}(\mathrm{~L}=\mathrm{I})$ has a spherical form with radius $\approx 8 \AA$, whereas $L=I I$ is a truncated sphere with the same radius and a distance of about $5.5 \AA$ from $\mathrm{Li}^{+}$to the "section plane". Hence, the effective sizes of the 1:4 complexes with II are essentially less than the size of the complexes with $\mathbf{I}$. This corresponds to a less effective solvation of the latter, which is probably related to its smaller $|\Delta H|$ values in comparison with complexes of II.

Another possible source of errors upon estimating $\Delta(\Delta H)_{\mathrm{I}, \mathrm{II}}$ is the exclusion of the anion from the present theoretical study. The point is that thiocyanates of $\mathrm{Li}^{+}$and $\mathrm{Na}^{+}$in acetonitrile can form both separated solvates and contact ion pairs [24].

The following question arises: it is possible to predict the complexation properties of podands in terms of additive schemes or correlation relationships? In fact, such an opportunity can be realized if the cation interacts in the same way both with donor atoms of the podand and with donor atoms of its fragments. The results obtained here and in ref. 20 show differences between bonds of $\mathrm{M}^{+}$with oxygen atoms of the methoxy group in its 
complexes with I and II, and corresponding bonds with the oxygen atoms of the polyether chain in $\mathrm{M}^{+} \cdot\left[\mathrm{R}-\mathrm{O}-\left(-\mathrm{CH}_{2}-\mathrm{CH}_{2}-\mathrm{O}-\right)_{n}-\mathrm{R}\right]$. It proves the impossibility of the simulation of the podand complexes and the prediction of their complexation ability, on the basis of information about the structure and energetics of the complexes of a cation with selected fragments of these polydentate agents.

\section{ACKNOWLEDGEMENTS}

We thank Dr. D. Feil and Dr. S. Harkema for some fruitful discussions.

\section{REFERENCES}

1 F. Vögtle and E. Weber, Angew. Chem., Int. Ed. Eng., 18 (1979) 753-776.

2 V.I. Evreinov, Z.N. Vostoknutova, V.E. Baulin, V.Kh. Syundyukova and E.N. Tsvetkov, Zh. Obshch. Khim., 59 (1989) 73.

3 V.I. Evreinov, V.E. Baulin, Z.N. Vostroknutova, N.A. Bondarenko, V.Kh. Syundyukova and E.N. Tsvetkov, Izv. Akad. Nauk SSSR, Ser. Khim., (1989) 1990.

4 V.I. Evreinov, Z.N. Vostoknutova, V.E. Baulin, V.Kh. Syundyukova and E.N. Tsvetkov, Zh. Obshch. Khim., 59 (1989) 67.

5 V.P. Solov'ev, L.V. Govorkova, O.A. Raevskii, V.E. Baulin, V.Kh. Syundyukova and E.N. Tsvetkov, Izv. Akad. Nauk SSSR, Ser. Khim., (1991) 575-581.

6 A.Yn. Tsivadze, A.V. Levkin, S.K. Bondareva, V.E. Baulin and E.N. Tsvetkov, Zh. Neorg. Khim., 36 (1991) 2445.

7 F. Vögtle and E. Weber (Eds.), Host-guest complex chemistry - macrocycles. Synthesis, structure, applications, Springer, Berlin, 1985.

8 H.J. Buschmann, in I. Bernal (Ed.), Stereochemistry of organometallic and inorganic compounds, Vol. 2, Elsevier, Amsterdam, 1987.

9 N.A. Bondarenko and E.N. Tsvetkov, Zh. Obshch. Khim., 59 (1989) 1533.

10 N.A. Bondarenko, E.N. Tsvetkov, E.I. Matrosov and M.I. Kabachnik, Izv. Akad. Nauk SSSR, Ser. Khim., (1979) 432.

11 V.P. Solov'ev, E.A. Vnuk, N.N. Strakhova and O.A. Raevskii, Sci. Technol. Rev., Chem. Thermodynamics and Equilibrium, VINITI, Moscow, 7 (1991) 373 (in Russian).

12 A.A. Varnek, A.S. Glebov, O.M. Petrukhin and R.P. Ozerov, Koord. Khimi., 15 (1989) 600.

13 A.A. Varnek, A.S. Glebov, O.M. Petrukhin and R.P. Ozerov, Koord. Khim., 15 (1989) 740.

14 N.L. Allinger, J. Am. Chem. Soc., 99 (1977) 8127.

15 J. Cailles and P. Claverie, Acta Crystallogr., Sect. A, 31 (1975) 448.

16 N. Gresh, P. Claverie and A. Pullman, Int. J. Quantum Chem., 13 (1979) 243.

17 S.R. Cox and D.E. Williams, J. Comput. Chem., 2 (1981) 304.

18 R.J.M. Le Fevre, Adv. Phys. Org. Chem., 3 (1965) 1.

19 A.Yu. Tsivadze, A.A. Varnek and V.E. Khutorsky, Coordination compounds of metals with crown ligands, Nauka, Moscow, 1991.

20 A.A. Varnek, G. Morosi and A. Gamba, J. Phys. Org. Chem., 5 (1992) 109.

21 M.L. Connolly, J. Appl. Crystallogr., 16 (1983) 548.

22 MOPAC5, QCPE No. 589.

23 S.I. Drakin and M.Kh. Karapetyants, Structure of Matter, Nauka, Moscow, 1973.

24 G.A. Krestov (Ed.), Ion solvation, Nauka, Moscow, 1987. 